Having read Michison \& Khanna's letter, I wonder whether the answer to the question lies in the emotionally distressed state the actor puts him or herself into while acting the role, and the perception of the candidate not responding to this sufficiently; whereas the examiner, who is not emotionally aroused, is less likely to down-score the candidate.

It is a pity that Mitchison \& Khanna's findings were not published in a full-length article because I would like to know more.

1 Mitchison S, Khanna P. Role players' experience of psychiatric examinations. Psychiatrist 2010; 34: 542-3.

2 Whelan P, Church L, Kadry K. Using standardized patientss marks in scoring postgraduate psychiatry OSCEs. Acad Psychiatry 2009; 33: $319-22$

Paul J. Whelan is consultant psychiatrist, Central and North West London NHS Foundation Trust, London, email: paul.whelan@nhs.net

doi: 10.1192/pb.35.3.118b

\section{Are reminders effective in reducing non-attendance?}

Rajasuriya et al highlight an important issue of non-attendance among out-patients and look at how to deal with this effectively. Their results show a reduction in non-attendance rates after using reminders in the form of letters and telephone calls. Their study identified several risk factors for nonattendance such as affordability or patient's level of education. However, they have overlooked many others.

The one important factor Rajasuriua et al failed to mention is the possibility of patients being admitted to hospital, whether for physical or mental health concerns. This could have led them to miss their out-patient appointments.

One significant issue raised in their study is in relation to healthcare services in Sri Lanka. These are not based on geographically designated catchment areas, therefore individuals can access the clinic of their choice in any part of the country. This means that some of the non-attendees in one service might have attended another service. Unless we have more information in relation to this, it would be difficult to make judgement about risk factors (male gender, substance use, bipolar disorder, schizophrenia, etc.) of non-attendance with any certainty (increased or decreased risk) and the real impact of reminders. It is quite possible that people might have shopped around for doctors and were planning to attend their next appointment anyway (with or without reminders).

In order to evaluate the effectiveness of reminders in reducing non-attendance, the design of the study should have been that of an intervention study, i.e. randomising non-attendees to an intervention (reminders) and control (no reminders) group. This is the only way of dealing with so many characteristics or risk factors mentioned in the study. This is important because all baseline characteristics that affect attendance and differ between treatment groups could potentially confound the relationship between reminders and non-attendance. Also, randomisation takes care of unknown confounding factors that are not identifiable, and these factors are distributed equally among treatment groups. Thus, randomisation can provide a degree of assurance about the comparability of the study groups that is simply not possible in any observational study design. ${ }^{2}$ I give credit to the authors for acknowledging the need of randomisation in the limitations of their study. I still feel, however, that it is difficult to draw any meaningful inferences from this study due to the drawbacks associated with the study design.

1 Rajasuriya M, de Silva V, Hanwella R. Effectiveness of reminders in reducing non-attendance among out-patients. Psychiatrist 2010; 34: 515-8.

2 Hennekens $\mathrm{CH}$, Burning JE. Epidemiology in Medicine. Little, Brown \& Co, 1987.

Mohinder Kapoor is specialty registrar (ST5) in old age psychiatry, South West Yorkshire Partnership NHS Foundation Trust, Batley, email: moekpr@yahoo.co.uk

doi: $10.1192 / \mathrm{pb} .35 .3 .119$ 